\title{
PODIATRIST'S ADVICE FOR MARATHON CASUALTY MANAGEMENT
}

\author{
R. GRAHAM, MChS, SRCh, Podiatrist
}

19A High Street, CHELSMFORD, Essex

The function of the podiatrist in the treatment of marathon runners is not widely understood, moreover the athletes themselves have a mistaken view of the podiatrist's skills. The podiatrist's role is not only to prescribe and dispense orthoses, but also to advise, not always realised by other professions and by athletes.

A major problem that has been created by the current popularity of long distance running is that many of the participants are solitary, or group runners, but are not often members of an athletic club. They seldom have the help and support of experienced runners or coaches, and in addition rely on the 'running press' for advice on matters of training and injuries. It therefore follows that in common with all other disciplines in the sports injury field a responsibility rests with the podiatrist to check that any sports patient is following a sensible routine in his training schedule.

Advice on training would include information on warming-up exercise before running and exercise on completion of the run. In addition attention must be paid to the terrain commonly covered, including the surfaces. It is not uncommon for an athlete to experience symptoms which can be resolved by the introduction of grass instead of tarmac, or by the elimination of downhill running.

After general advice the lower limbs can be examined to determine the ability of the runner to withstand comfortably the trauma of distance running. It seems clear that some foot-types will always be fatigued or easily injured, e.g. the rigid cavus foot or marked ankle equinus. It is arguable that the best advice for these problems may be to avoid road running completely. The podiatrist will check for limb or trunk abnormality so that these may be referred if necessary. Limb length differences are a cause of injuries and small variations which are not significant in walking may become a cause of pain in prolonged running (Subotnick, 1975; Brody, 197 ).

A specific examination of the foot can now take place, checking for forefoot and rearfoot alignments and the foot's alignment to the leg. In addition the general condition of the skin and nails will be noted. Help can be given in the prevention of blistering and chafing of the skin and sub-ungual haematoma.

Many athletes consult podiatrists only when pain or other symptoms present themselves. This is unfortunate since much of the pathology that some runners experience is predictable and the examination briefly described above would uncover those most at risk of lower limb injury before it occurs. Whilst it is impractical to suggest that all intending runners are examined before they start, it should be stressed that they should not ignore early signs and symptoms.

Skin and nail damage can often be avoided by attention to the obvious in footwear. Socks should be wool or cotton and the nylon content kept to a minimum (less than $40 \%$ ). They should fit well and stay in place. Shoes should not be severely or unevenly worn so that they are unstable. Laces should be of an adequate length and securely tied. It would be possible to discourse at length about running shoes but there is little evidence to support the purchase of the most expensive shoes. It is better to be able to replace a badly worn shoe when necessary rather than prolong its use because of its purchase price. Any skin site especially prone to blistering should be well greased before running or protected with a sheet gel (e.g. 'Second Skin') and not with adhesive waterproof plaster.

Nail damage is difficult to prevent and chronic subungual haematoma may be due to ill fitting shoes such as a shallow toe box. It may be due, however, to a forefoot functional distortion or condition, e.g. Hallux limitus. If the nail trauma is unavoidable then a layer of sponge or silicone will reduce the likelihood of injury.

The whole range of injuries often called 'over-use injuries' are initially treated using padding and strapping to maintain foot alignment. This would be in conjunction with physiotherapy as required. Many common conditions such as plantar fasciitis or intermetatarsal neuritis may be resolved using strapping and temporary orthoses. If a lower leg or foot mis-alignment is present then the condition will probably recur. Only if the abnormality is likely to lead to a repeat of this or another injury would the use of permanent orthoses be beneficial. Sperryn noted in 1983 that as few as half of patients issued with permanent orthoses continue their long term use. It is arguable that permanent casted orthoses should only be provided after some measure of injury or pain relief has been demonstrated with temporary orthoses.

The use of orthoses to control functional foot imbalances which are producing symptoms elsewhere in the body have been described, e.g. in chondromalacia patellae and shin splints (Subotnick, 1975; Brody 19 1. The podiatrist is not likely to be the first practitioner to treat these conditions. 
From experience at the London marathon the podiatrist is second in popularity among the runners only to the physiotherapist. In the period immediately following the finish most runners requiring assistance are of the 'tender loving care' type. The largest group are muscle fatigue and cramp. The podiatrist can provide massage and aid recovery. The London finish frequently overloads the available physiotherapists. Skin and nail abrasions provide the next largest group. These can be cleaned and dressed with non-adherent dressings. Subungual haematomas can be drained by piercing the nail. This must be done before the blood coagulates. Various methods are suggested but a pinpoint nail drill is the least painful. If performed in the hour or two after the finish then spontaneous avulsion of the nail can be prevented.

A much smaller group of finishers will have more serious injuries. These may include metatarsal or phalangeal fractures, calcaneal epiphysitis, muscle or tendon tears, shearing of the plantar fascia. In most cases these do not commonly receive plaster casts, but may be immobilised and protected with strapping and padding. Phalangeal freactures can be rendered relatively comfortable with four or five layers of tubigauze alternated with a liberal application of a plastic spray dressing (opsite). This sets fairly hard and can remain in place until healed.

The number of serious injuries is unlikely to exceed $0.5 \%$ of the total number of runners, the abrasion and superficial problems may be of the order of $5 \%$. One podiatrist per thousand runners should be sufficient to provide adequate cover. These suggestions are based on experience at the London Marathon (Tunstall Pedoe et al, 1984).

\section{References}

Brody, D., 1980. Running Injuries. Ciba Clinical Symposia 32 (4). Sperryn, P. N., 1983 "Evaluation of orthoses". Brit.J.Sports Med. 17.

Subotnick, S., 1975. Podiatric Sports Medicine. New York: Futura.

Tunstall Pedoe et al, 1984. British Medical Journal, 5th May, reprinted pages 